\title{
ARTIGO
}

\section{REFLEXÕES ACERCA DA REPRESENTAÇÃO DE DOCUMENTOS E A RECEPÇÃO INFORMACIONAL}

\section{REFLECTIONS ABOUT DOCUMENT REPRESENTATION AND INFORMATION RECEPTION}

${ }^{1}$ Giovana Deliberali Maimone

Universidade de São Paulo

\section{Correspondência}

Giovana Deliberali Maimone

Universidade de São Paulo

São Paulo, SP - Brasil.

E-mail: gdmaimone@usp.br

Submetido em: 28/11/2018

Aceito em: 09/04/2019

Publicado em: 10/04/2019

Checagem Antiplagiarismo

turnitind

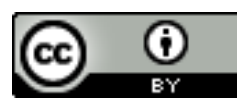

JITA: ID. Knowledge representation

e-Location ID: 019015 
RESUMO

Apresenta reflexões sobre representação documentária, relacionando-a à recepção informacional pelo indivíduo. A Ciência da Informação opera com o tratamento de documentos tendo a preocupação de tornar o usuário informado, para que, a partir das informações recebidas seja possível a geração de conhecimento. A metodologia empregada para desenvolvimento deste trabalho constituiu-se de levantamentos bibliográficos em bases de dados nacionais e estrangeiras, possibilitados pelo Sistema Integrado de Bibliotecas da Universidade de São Paulo (SIBI/USP). Verificou-se que existem relações entre os conceitos uma vez que a recepção informacional é otimizada por meio da adequada e fidedigna representação documentária, que perpassa processos cognitivos e compulsoriamente comunicativos para sua apropriação. Possibilita-se, deste modo, o desenvolvimento intelectual, científico, tecnológico e cultural da sociedade através do processo representativo. $\mathrm{O}$ ato de receber uma informação não propicia obrigatoriamente a geração de novos conhecimentos, porém é evidente que a área da Ciência da Informação pode auxiliar a partir da representação aliada aos processos cognitivos que envolvem o pensamento humano.

\section{PALAVRAS-CHAVE}

Representação documentária. Recepção da informação. Cognição. Comunicação.

\section{ABSTRACT}

It presents reflections of documentary representation, relating it to the informational reception by the individual. The Information Science operates with the handling of documents with the concern of making the user informed, so that, from the information received is possible the generation of knowledge. The methodology used to develop this work consisted of bibliographic surveys in national and foreign databases, made possible by the Integrated Library System of the University of São Paulo (SIBI / USP). It was verified that there are relations between the concepts since the informational reception is optimized through the proper and reliable documentary representation, which goes through cognitive and compulsorily communicative processes for its appropriation. In this way, the intellectual, scientific, technological and cultural development of society can be achieved through the representative process. The act of receiving information does not necessarily imply the generation of new knowledge, but it is clear that the area of Information Science can help from the representation allied to the cognitive processes that involve human thought.

\section{KEYWORDS}

Information processing. Information reception. Cognition. Communication. 


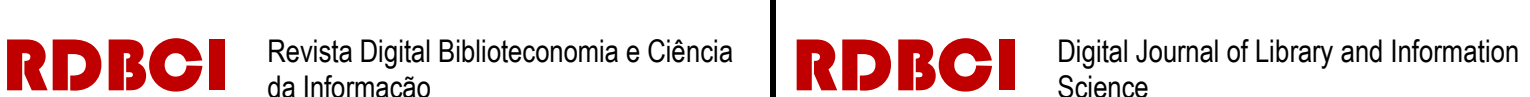

\section{Introdução}

A categoria da recepção informacional integra diversas camadas da sociedade que, de acordo com níveis instrucionais e capacidade de assimilação geram em maior ou menor grau, o conhecimento. Tais camadas podem segmentar-se em níveis distintos que variam desde as faixas menos favorecidas que possuem poucos recursos de acesso/assimilação informacional até as mais especializadas como são as comunidades universitárias portadoras de terminologia própria, linguagem e conhecimento em permanente desenvolvimento.

A informação circula socialmente, isto é, atua como fluxo que possibilita recepção para geração de conhecimento, passando forçosamente pelo estoque acumulado pelo usuário. Nesse sentido, a operação cognitiva entre a nova informação e o conhecimento preexistente consiste na atribuição de significados.

O acesso físico não enseja por si só a operação cognitiva, ou seja, o acesso deve estar sempre relacionado à orientação de valor e capacidade de recepção do usuário. Assim, tarefas como interpretação, formulação de conceitos e aprendizagem devem estar sempre associadas à representação documentária e busca de informação, tendo os receptores como peça central dos sistemas, atentando-se às questões de identidade e propósitos dos mesmos.

Embora áreas como as Ciências da Comunicação e da Informação tenham privilegiado durante algum tempo a atividade emissiva, contemporaneamente percebe-se uma preocupação com a categoria da recepção.

\begin{abstract}
A informação não é um dado. Ela se constrói no encontro entre duas dinâmicas: a dinâmica de quem "emite", de quem "enuncia" (o enunciador) e a dinâmica de quem "recebe" o enunciado (o enunciatário). Ela ocorre sempre num espaço onde as posições de quem "fala" e de quem "ouve" são intercambiadas, num jogo de forças permanente (CINTRA et al., 2002, p. 10).
\end{abstract}

Abordar a informação como insumo fundamental para o processo interpretativo é relevante por aproximar questões de transformação / reconstrução de conhecimentos, prevendo-se a impossibilidade de fixação de significados.

As obras - mesmo as maiores, ou, sobretudo, as maiores - não têm sentido estático, universal, fixo. Elas estão investidas de significações plurais e móveis, que se constroem no encontro de uma proposição com uma recepção. Os sentidos atribuídos às suas formas e aos seus motivos dependem das competências ou das expectativas dos diferentes públicos que delas se apropriam. Certamente, os criadores, os poderes ou os experts sempre querem fixar um sentido e enunciar a interpretação correta que deve impor limites à leitura (ou ao olhar). Todavia, a recepção também inventa, desloca e distorce (CHARTIER, 1999, p. 9). 


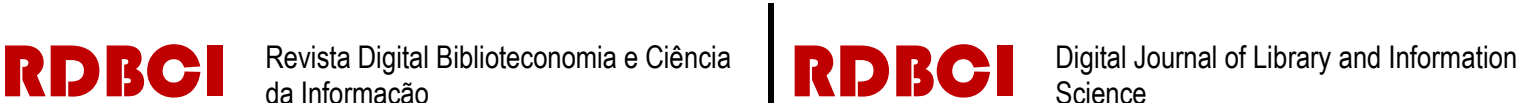

Cientes destas questões é papel do profissional tratar a informação para torná-la disponível, obedecendo a critérios pré-estabelecidos para representar os documentos (normas, procedimentos e ferramentas próprias utilizadas e desenvolvidas pela Ciência da Informação) de modo que possa evidenciar seus conteúdos. A metodologia empregada para desenvolvimento do trabalho e análise dos materiais encontrados constitui-se de levantamentos bibliográficos em algumas das bases de dados nacionais e estrangeiras, possibilitados pelo Sistema Integrado de Bibliotecas da Universidade de São Paulo (SIBI/USP), são elas: Biblioteca Digital de Teses e Dissertações (BDTD), Base de Dados Referencial de Artigos de Periódicos em Ciência da Informação (BRAPCI) e Portal de Periódicos da Coordenação de Aperfeiçoamento de Pessoal de Nível Superior (CAPES). Os textos estudados encontram-se nas seguintes áreas: Ciência da Informação, Ciência da Comunicação, Ciência Cognitiva e Linguística e fundamentam a ideia de tangenciamento da categoria emissiva com a receptiva. Este trabalho traz logo em seguida reflexões sobre a representação de documentos e a recepção informacional realizada a partir de atividades que permeiam a interação usuário/acervo, finalizando com algumas considerações sobre o tema.

\section{Representação de documentos e recepção da informação}

A proposição deste estudo pauta-se nos conceitos de representação documentária e recepção de informação sendo que, para o primeiro trabalha-se de modo genérico atividades/produtos de tratamento documentário, evidenciando o elemento representativo como aquele intermediário que "está no lugar de outro sem o sê-lo"; já para o segundo a abordagem é da natureza do usuário e o modo de apropriação informacional, único de cada indivíduo. Tal relação é estudada para fins de aprimoramento dos produtos documentários.

Receber informação supõe, inicialmente, que esta esteja inserida em dispositivo que lhe permita acesso. Porém, tal disponibilização não garante apropriação informacional e incremento intelectual dos usuários, já que para a efetivação destes processos é necessária uma bagagem de conhecimento anterior, além da capacidade cognitiva de cada indivíduo. "Uma vez processada, a informação submete-se a julgamentos subjetivos associados às intenções, incertezas, significados" (TÁLAMO; MAIMONE, 2012, p. 7). Sendo assim,

[...] para que uma informação possa ser processada pelo indivíduo este deve encontrar, em sua rede cognitiva, algum ponto ao qual a informação nova possa ser conectada (a competência enciclopédica) de forma a conseguir situar a informação nova num conjunto maior (a rede cognitiva) [...] supõe a existência de um conhecimento anterior (a rede cognitiva) bem como a disposição de alterar, completar ou rever este conhecimento (SMIT, 2012, p. 93). 


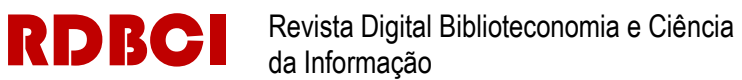

No sentido de enfatizar o conceito de informação concebido para este trabalho reiterase a afirmação de Tálamo (2004, p. 1):

\begin{abstract}
Informação é sempre fluxo e para o sujeito ela funciona como troca com o mundo exterior, o que lhe confere seu caráter social. Assimilada, interiorizada e processada por um sujeito específico, ela é a base para sua integração no mundo, propiciando ajustes contínuos entre o mundo interior e o mundo exterior.
\end{abstract}

Assim, informação é insumo e veículo para geração/agregação de conhecimentos. O usuário produz sentido à uma informação ao recebê-la e compreendê-la, fato que, de acordo com Pinto $(2010$, p. 6$)$ "se fundamenta nas suas vivências, que por sua vez, se baseiam no espaço e no tempo".

Berlo (1999) em seu livro "O processo da comunicação: introdução à teoria e à prática" sintetiza em um quadro quais seriam os ingredientes para transmissão da informação, ou seja, fonte, mensagem, canal e receptor, conforme ilustra a figura abaixo.

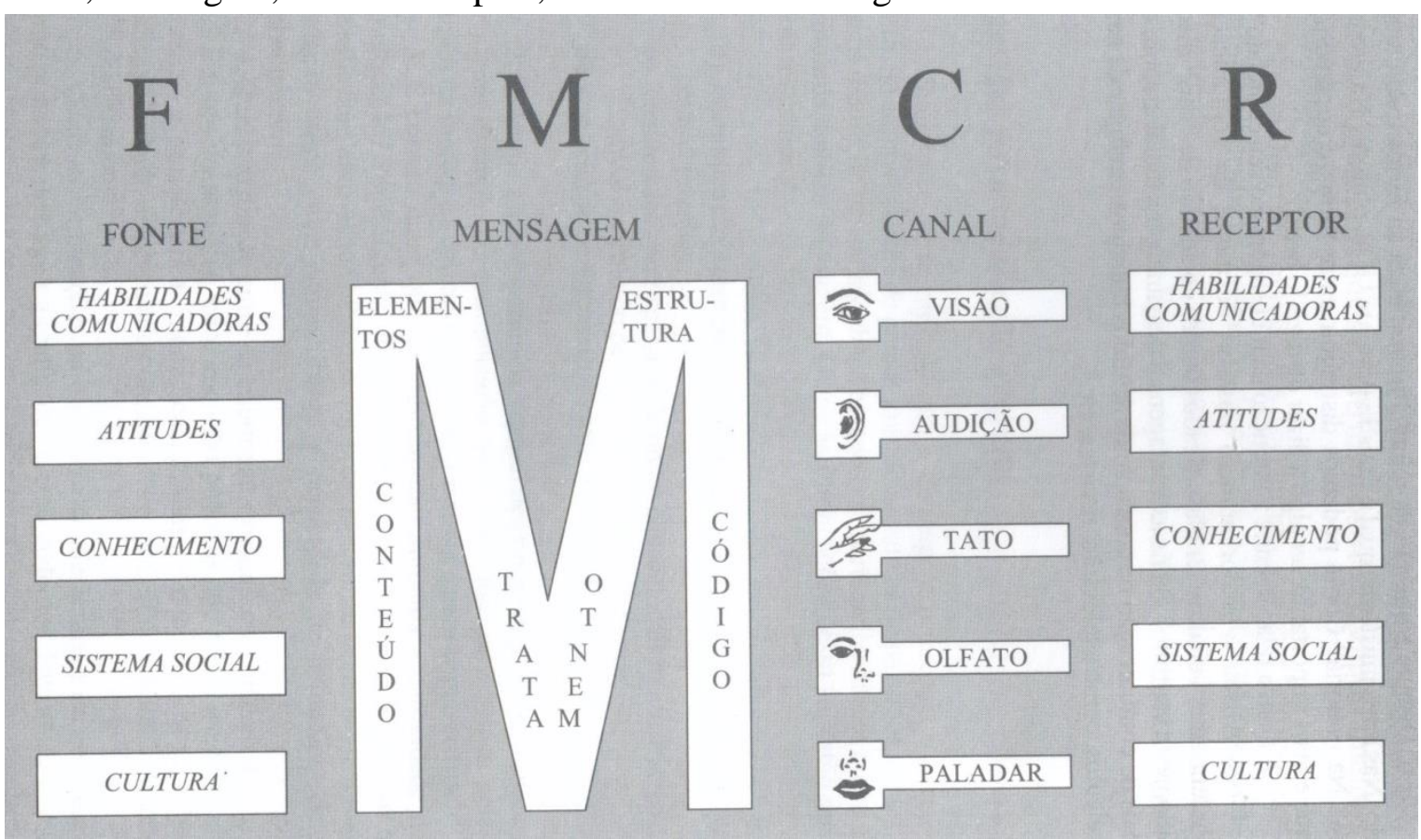

Figura 1. Ingredientes da comunicação.

Fonte: Berlo (1999, p. 74).

A fonte é responsável por codificar a mensagem a fim de torná-la acessível. Neste caso ela agregaria os seguintes fatores que aumentariam sua fidelidade: habilidades comunicadoras (a escrita, a palavra, a leitura, a audição e o pensamento), atitudes, níveis de conhecimento (geral/especializado), sistema sociocultural do qual faz parte (determinam as palavras escolhidas, os objetivos e os canais para realizar a comunicação). "Aquele que é fonte num instante já foi receptor. [...] O mesmo vale para o receptor, que também pode ser visto como

\begin{tabular}{|c|}
\hline RDBCl: Rev Diait Bibliotecon Cienc Inf \\
\hline
\end{tabular}




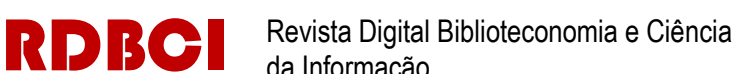 da Informação

fonte" (BERLO, 1999, p. 52). Neste sentido, os elementos atribuídos à fonte são os mesmos para o receptor já que para uma melhor compreensão ambos devem dominar equilibradamente os mesmos fatores.

O ingrediente mensagem diz-se do "produto físico real do codificador-fonte" (BERLO, 1999, p. 55) ou, o discurso, a escrita, a pintura, os gestos, etc. Esta concepção é pertinente para a organização do conhecimento no que se refere principalmente às linguagens documentárias por tratar de questões como código, conteúdo e tratamento dos materiais que carregam a mensagem. As escolhas de código (linguagem), conteúdo e tratamento (formas de representação) devem ser pautadas no conhecimento do usuário, do acervo e dos objetivos institucionais. $\mathrm{O}$ canal $^{1}$ pode ser entendido como o meio pelo qual a mensagem será distribuída.

É possível neste momento realizarmos uma analogia ao "funcionamento" do sistema nervoso central (transmissão sináptica ${ }^{2}$ ) que trabalha por meio de estímulos.

O sistema nervoso produz e regula todos os aspectos das funções do corpo humano e sua complexidade parece infinita. Bilhões de neurônios agrupados para diferentes funções checam, constantemente, o meio interno da nossa anatomia e o universo exterior: luz, tato, pressão, som, equilíbrio, imagens, concentrações de muitas substâncias, dor, emoção, consciência (LOPES et. al., 1999, p. 168).

Para o funcionamento do cérebro é essencial a presença de “estímulos/impressões” (luz, calor, som, tato) externas que propiciam a verificação da relação entre ambiente interno (homem) e externo (mundo) (exemplo: se tocamos em algo gelado temos a sensação de frio resultado). Em ambos os casos, é necessário um impulso para que os processos aconteçam. No caso documentário, a informação é o estímulo para o conhecimento, e quanto mais imparcial e fidedigna for ao original maior será a chance de sucesso na recuperação (resultado).

Em artigo publicado em 2013, Melo relaciona alguns processos cognitivos com o objetivo de auxiliar a representação temática da informação. Embora bastante pertinente e aprofundado interessa-nos mais particularmente um trecho de suas considerações finais quando ressalta que:

Uma das características comuns à consciência, à atenção, à representação mental (esquemas e proposições) e à memória é o seu funcionamento através de redes semânticas e relacionais. Isto indica familiaridade do pensamento humano com as conexões com a representação da informação que se estruturam em forma de redes, quer sejam hierarquizadas ou não. Iniciativas desse tipo tornam intuitivas as representações da informação sob esse princípio e facilitam sua compreensão pelo usuário (MELO, 2013, p. 78).

\footnotetext{
${ }^{1}$ Em Ciência da Informação os canais são apresentados a partir de sistemas informacionais.

2 "Mecanismos que caracterizam a comunicação química entre neurônios" (LOPES et al. 1999, p. 168).

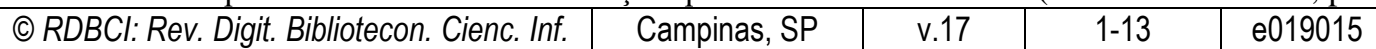




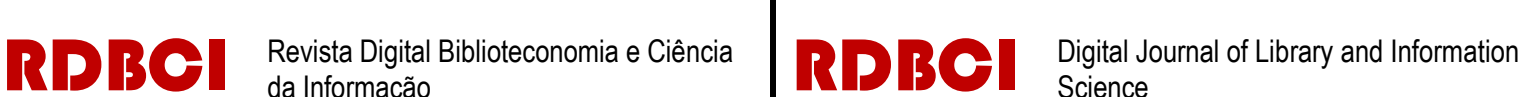

É possível deduzir então que o conceito de rede (relacional e semântica) permeia todo processo de interpretação / representação informacional fato que evidencia algumas linguagens documentárias (tesauros, ontologias, web semântica) estarem pautadas neste tipo de estruturação, assim como outras ferramentas de organização do conhecimento. Neste sentido, as formas de representação da informação, se realizadas assemelhando-se ao processo de pensamento humano, tem mais chances de serem melhor recebidas.

Dentre as principais teorias de desenvolvimento cognitivo, ressalta-se a abordagem do processamento da informação que estuda mais especificamente a questão da compreensão textual que envolve de forma direta "codificação semântica, aquisição de vocabulário, criação de modelos mentais e compreensão das ideias do texto" (NEVES, 2006, p. 41). Sistemas de classificação, operações terminológicas para elaboração conceitual (tesauros), mapeamento de informações (mapas conceituais) são exemplos destes instrumentos em Ciência da Informação. $\mathrm{O}$ processamento da informação "busca compreender como a informação é interpretada, armazenada, recuperada e avaliada através da compreensão de processos específicos [...] tais como percepção, memória, inferência, avaliação da informação e uso de regras" (ANDALÉCIO, SOUZA, 2008, p. 76). Adaptando o conceito de cognição ao trabalho de processar / representar a informação Varela (2008) revela que:

\begin{abstract}
A cognição é um conhecimento relevante para que o profissional da informação possa compreender e delinear a trajetória do usuário no processo de busca da informação e da construção dos meandros da cognição na apreensão do conhecimento (VARELA, 2008, p. 36).
\end{abstract}

Esta colocação se mostra importante por reiterar a função primordial da Ciência da Informação, ou seja, promover o encontro do usuário com a informação, visto que as "teorias, métodos e procedimentos que compõem o corpus da Ciência da Informação só tem significado quando o usuário encontra a informação útil” (VARELA, 2008, p. 40, grifos da autora).

Os estudos de Venâncio e Borges (2006) que aprofundam conceitos sobre a cognição situada (não abordada nesta pesquisa) revelam que uma das maiores contribuições que a Ciência Cognitiva pode oferecer à Ciência da Informação reside na organização e tratamento da informação especificamente quanto ao uso dos sistemas, na "formulação dos requisitos para recuperação da informação" (VENÂNCIO, BORGES, 2006, p. 35, grifo nosso). Entende-se que tais requisitos auxiliariam no entendimento do raciocínio humano a fim de representar/estruturar/codificar os documentos para serem encontrados, sendo que a busca do usuário percorreria o mesmo percurso.

Conscientes de que a adequada representação da informação pode agregar valor aos conhecimentos dos indivíduos, a Ciência da Informação deve trabalhar de modo conexo às 


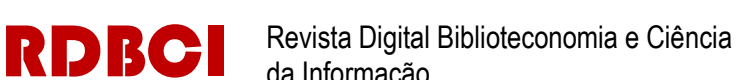

necessidades destes lembrando que somente o conhecimento explícito pode ser tratado. Conforme explica Smit (2012, p. 85):

[...] a informação, para poder ser utilizada por mais pessoas sem limitações de tempo e espaço, supõe que a mesma tenha sido "documentada", ou seja, registrada. [...] Informação registrada equivale ao conceito de documento [...]. (grifos da autora).

Além desta condição de "registro", necessária à realização das atividades documentárias, é preciso considerar ainda os dois grandes pólos da cadeia comunicativa (emissão e recepção) como peças-chave à recuperação informacional.

\begin{abstract}
Las atividades emissiva y receptiva son interdependientes, se condicionan entre sí: al producir um mensaje o texto, el emissor normalmente há de anticiparla interpretación-respuesta de su receptor; al interpretarlo, el receptor normalmente propone ciertas hipótesis sobre los propósitos del emissor, sobre la forma textual y contexto, etc. (ABRIL, 1997, p. 22).
\end{abstract}

Deve existir, portanto, uma correlação semântica entre emissor e receptor, sendo que aos profissionais da informação cabe a emissão quando da elaboração dos produtos documentários para seu(s) público(s) (TÁLAMO; MAIMONE, 2012). "Vale a pena observar, nesta altura, que o significado do emissor envolve a noção de intenção e o significado do receptor, a noção de valor" (LYONS, 1977, p. 36, tradução livre). Assim, e por consequência, "[...] parece razoável, de um modo geral, dizer que quanto maior for o valor de surpresa de uma determinada notícia, tanto mais significativa ela é” (LYONS, 1977, p. 45, tradução livre).

No ambiente comunicacional, muitas vezes dominado por mídias massivas, vale uma crítica enunciada por Lara e Tálamo em artigo de 2008 quando afirmam que "os media uniformizam seu público ao contrário de implementar um universo de alternativas, como se supõe que seja uma das funções das TICs" "(LARA, TÁLAMO, 2008, p. 3). Afirma-se, portanto, que a ideia de unicidade pautada nas semelhanças dos indivíduos e apresentadas como formas únicas de transmissão do mundo escamoteiam a diversidade linguística e a heterogeneidade social dos povos.

A categoria da recepção deve atribuir significado à informação recebida, uma vez que os materiais, embora tratados por muito tempo como portadores de apenas um sentido, são "plurais e móveis" (CHARTIER, 1999). Existem aspectos subjetivos advindos da atividade de interpretação, tanto por parte do profissional quanto do usuário, que devem ser considerados e estudados "compreendendo que a representação da informação é um processo que se desenvolve a partir de ações cognitivas" (SAMPAIO, DANTAS, NEVES, 2017, p. 29).

\footnotetext{
${ }^{3}$ Tecnologias de Informação e Comunicação.
} 
Portanto, a ideia de organizar os documentos de forma a priorizar a recepção deve envolver a análise do contexto social em que a mensagem circula, a fim de definir com mais precisão sua representação, recorrendo-se para isto, entre outros, aos estudos da linguística e da terminologia. A representação da informação é considerada complexa, pois perpassa categorias comunicacionais que se sobrepõem na emissão e na recepção, tangenciando a condição/formação social, econômica e cultural de um determinado público e/ou públicos; neste sentido, o profissional da informação deve realizar os processos de representação consciente das situações e expectativas dos usuários.

O comprometimento em descrever um registro do conhecimento relacionando-o com o contexto social no qual a sua mensagem irá circular é uma preocupação recorrente entre os profissionais que organizam a informação, no entanto, nem sempre foi assim (SOUZA, 2017, p. 27).

Partindo-se da premissa de que o ambiente de qualquer organização que trabalha com informação está pautado nas relações usuários/documentos, apresenta-se a figura abaixo no intuito de caracterizar suas etapas de modo simplificado.

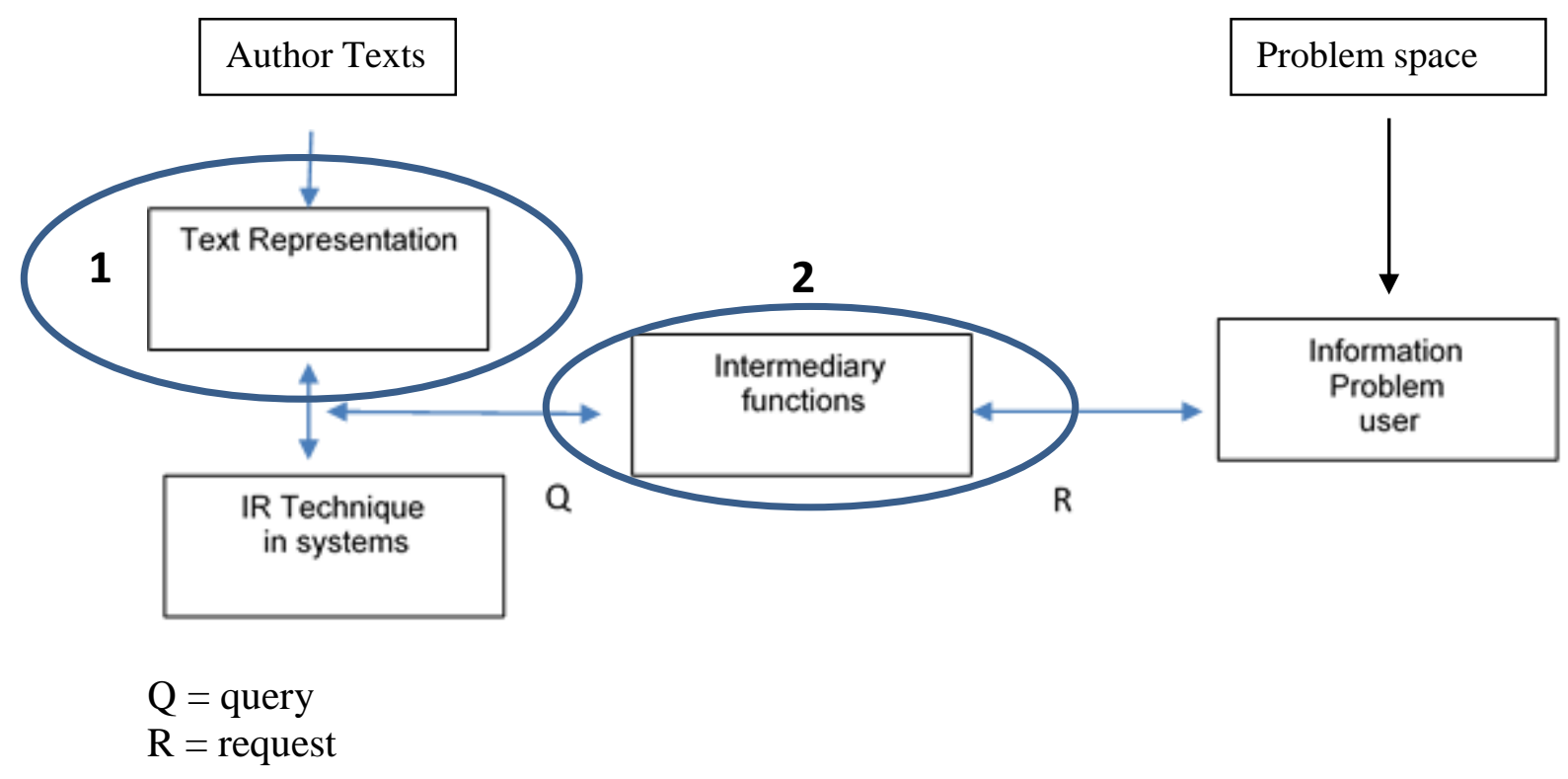

Figura 2. Modelo simplista de recuperação de informação.

Fonte: Adaptado de Ingwersen (1992, p. 55).

Este quadro diz respeito ao modelo simplista de recuperação de informação proposto por Ingwersen e Wormell em 1989, retomado em artigo do primeiro em 1992. Duas grandes áreas podem ser identificadas acima: uma relacionada especificamente ao usuário e seu problema de pesquisa e outra aos documentos (conhecimento registrado) e suas formas de tratamento para recuperação da informação. 


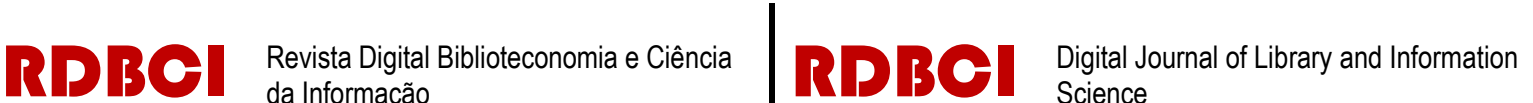

Interessa-nos especialmente enfatizar os elementos marcados com as numerações 1 e 2 (no quadro acima, fruto da adaptação da figura) que realizam funções específicas da representação informacional. As representações textuais (1) são informações retiradas do próprio documento que permitem acessar sua localização através de, por exemplo: nome de autor, título do texto, data da obra, assunto, etc.; além disso, são também realizadas atividades como elaboração do resumo documentário e atribuição de palavras-chave.

Às funções intermediárias (2) cabe o reconhecimento da solicitação do usuário, sua "tradução" para a linguagem do sistema (tesauros, vocabulários controlados) e a busca pelo material tendo como base a linguagem de indexação utilizada. Técnicas de recuperação da informação em sistemas dizem respeito aos operadores de busca como a lógica booleana ou busca truncada por exemplo.

Se as etapas 1 e 2 forem realizadas de modo adequado, respeitando o tipo de acervo existente e as necessidades informacionais dos usuários, o acesso à informação estará assegurado. A ação cognitiva da informação e as relações que mantém com o conhecimento acumulado está presente em ambas etapas acima explicitadas visto que tanto a elaboração textual como a atribuição e padronização de termos de assunto necessitam, entre outras, de interpretação e contextualização sempre com o objetivo de satisfazer os desejos informacionais dos usuários.

O contexto cognitivo aplicado ao campo da Ciência da Informação apresenta uma mudança de paradigma, antes centrado no acervo e na otimização das atividades de processamento da informação, para

[...] um modelo centrado no sujeito/usuário voltado para o aprendizado como processo contínuo de internalização de fundamentos conceituais, atitudinais, comportamentais e de habilidades necessárias à compreensão e interação permanente com o universo informacional e sua dinâmica (VARELA, 2008, p. 42).

Retomando informação como fluxo é possível refletir sobre a dinâmica que envolve o processo de recepção reconstruindo a partir do estudo de usuários, a interação / articulação conceitual com os produtos documentários oferecidos pelos centros de informação. $\mathrm{O}$ profissional pode apropriar-se da teoria da cognição para compreender os modos de aprendizagem e as habilidades intelectuais necessárias para realizar vínculos de sentido entre o documento e a informação a ser produzida. Possibilita-se, deste modo, o desenvolvimento intelectual, científico, tecnológico e cultural da sociedade através do processo representativo. 


\section{Considerações Finais}

O tratamento documentário, ou seja, aquele realizado sobre a informação é essencial para o desenvolvimento da sociedade pois é o responsável pelo acesso ao conhecimento. Tal atividade resulta em produtos documentários (resumos, índices, referências, entre outros) que favorecem essa mediação. Como já evidenciado acima a emissão sempre traz consigo uma intenção comunicativa, sendo que o valor quem oferece é o usuário, ou seja, a recepção. Por mais que se intente fixar um sentido, o significado é sempre dado pelo expectador. Neste caso, o máximo que se pode fazer é "tratar" fidedignamente os documentos para assegurar a confiança nos serviços de representação.

Aproximando a Ciência Cognitiva da Ciência da Informação infere-se que quanto mais semelhantes ao pensamento humano forem os processos/produtos documentários (representação) maiores também as chances de sucesso na recepção da informação pela semelhança do itinerário intelectual percorrido.

Independente do nível instrucional dos usuários, deve-se promover representações documentárias que favoreçam sua recepção. Por este motivo é essencial conhecer a linguagem e os desejos de informação, tendo em vista que o receptor pode ser, em algum momento, emissor. Para isso é relevante estabelecer feedbacks em relação ao uso efetivo dos produtos documentários disponibilizados pelos sistemas informacionais. Conforme explicitado anteriormente, o ato de receber uma informação não propicia obrigatoriamente a geração de novos conhecimentos, porém é evidente que a área da Ciência da Informação pode auxiliar a partir da representação informacional aliada aos processos cognitivos que envolvem o pensamento humano.

Longe da pretensão de aparar todas as arestas apontadas por este trabalho, prosseguimentos investigativos são fortemente recomendados para aprimorar e aprofundar conhecimentos na interface "emissão - tratamento - recepção" de informação.

\section{Referências}

ABRIL, G. Teoría general de la información. Madrid: Catedra, 1997.

ANDALÉCIO, A. L.; SOUZA, R. R. Ciência cognitiva e ciência da informação: paralelos. Informação \& Informação, v. 13, n. 1, p. 72-80, 2008. DOI: 10.5433/1981-8920.

CHARTIER, R. A ordem dos livros: leitores, autores e bibliotecas na Europa entre os séculos XIV e XVIII. Brasília: Editora Universidade de Brasília, 1999. 
CINTRA, A. M. M. et al. Para entender as linguagens documentárias. 2. ed. rev. e atual. São Paulo: Polis, 2002.

INGWERSEN, P. Information retrieval interaction. Michigan: Taylor Graham, 1992.

LARA, M. L. G. de; TÁLAMO, M. de F. G. M. Informação e produção de sentido: a integração da categoria recepção no processo documentário-informacional. Rumores Revista Online de Comunicação, Linguagem e Mídias, v. 1, n. 2, 25 jun. 2008.

LYONS, J. Semântica - I. Lisboa: Editorial Presença, 1977.

LOPES, A. C. P. et al. Aspectos moleculares da transmissão sináptica. Medicina, Ribeirão Preto, v. 32, p. 167-188, abr./jun. 1999.

MELO, A. V. C. Contribuições possíveis dos estudos sobre processos cognitivos para a representação temática da informação. Perspectivas em Gestão \& Conhecimento, v. 3, p. 67-79, 2013.

NEVES, D. A. Ciência da Informação e cognição humana: uma abordagem do processamento da informação. Ciência da Informação, Brasília, v. 35, n. 1, p. 39-44, jan./abr. 2006.

PINTO, L. P. A recepção da informação: apresentação ou representação? DataGramaZero, v. 11, n. 5, 2010.

SAMPAIO, D. A.; DANTAS, E. R. F.; NEVES, D. A. B. Nas entrelinhas da cognição: tópicos de representação da informação. Folha de Rosto, v. 3, n. 1, p. 24-31, 2017.

SMIT, J. W. A informação na Ciência da Informação. InCID: R. Ci. Inf. E Doc., Ribeirão Preto, v. 3, n. 2, p. 84 - 101, jul./dez. 2012.

SOUZA, E. G. As teorias documentárias e a organização da informação: a centralidade das categorias obra e usuário. In: CONGRESSO BRASILEIRO EM ORGANIZAÇÃO E REPRESENTAÇÃO DO CONHECIMENTO, 4., 2017, Recife. Anais... Recife, 2017.

TÁLAMO, M. F. G. M. A pesquisa: recepção da informação e produção do conhecimento. DataGramaZero, v. 5, n. 2, 2004.

TÁLAMO, M. de F. G. M.; MAIMONE, G. D. Acesso ao bem cultural via estudos de informação: reflexões teóricas. Datagramazero - Revista de Ciência da Informação, Rio de Janeiro, v. 13, n. 4, out. 2012.

VARELA, A. V. Informação, cognição e mediação: vertentes, contextos e pretextos. Revista Ibero-Americana de Ciência da Informação, v. 1, n. 1, p. 21-45, 2008.

DOI: 10.26512/rici.v1.n1.2008.891

\begin{tabular}{l|l|l|l|l|r|}
\hline (C) RDBCl: Rev. Digit. Bibliotecon. Cienc. Inf. & Campinas, SP & v.17 & $1-13$ & e019015 & 2019 \\
\hline
\end{tabular}




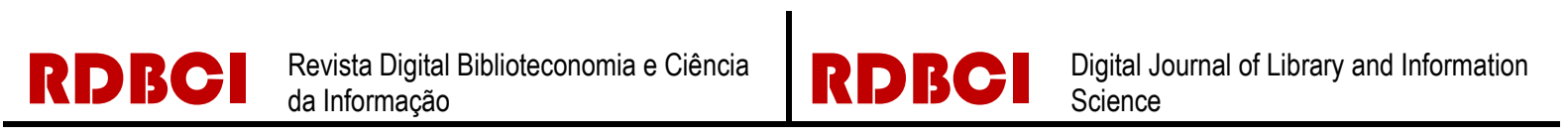

VENÂNCIO, L. S.; BORGES, M. E. N. Cognição situada: fundamentos e relações com a ciência da informação. Encontros Bibli: Revista Eletrônica de Biblioteconomia e Ciência da Informação, v. 11, n. 22, p. 30-37, 2006. DOI: 10.5007/1518-2924.2006v11n22p30 